Session 2125

\title{
Creating and Using a Performance Measure for the Engineering Design Process
}

\author{
Andrew Kline ${ }^{1}$, Edmund Tsang ${ }^{1}$, Betsy Aller ${ }^{1}$, Johnson Asumadu ${ }^{1}$, \\ Jim Morgan ${ }^{2}$, Steven Beyerlein ${ }^{3}$, and Denny Davis ${ }^{4}$
}

1. Western Michigan University, 2. Texas A \& M University, 3. University of Idaho, and

4. Washington State University

\section{Introduction}

Evaluation is the judgment or grading of past performance over a period of time. Assessment (measuring) is using past performance in order to make modifications (improvements) in future performances (Parker, et al., 2001). Assessment identifies an individual's or group's strengths, weaknesses that need to be addressed, and insights gained from the assessment that are transferable to other activities, situations, or contexts.

This paper describes both the methodology used to create an integrated performance measure, and the product of a two-day workshop session that resulted in a performance measure for the engineering design process. The new performance measure was created at Western Michigan University (WMU) by a team of fourteen faculty members and administrators representing the major branches of engineering - electrical, civil, mechanical, and chemical - as well as an ass ortment of other technical and non-technical disciplines. The methodology applied consists of (1) forming a team with diverse training and perspectives, (2) recruiting an unbiased facilitator versed in the methodology and familiar with the process area, (3) synthesizing a descriptive definition that a ccurately and completely describes the skill set being measured, (4) analyzing behaviors of an expert who displays outstanding performance in all dimensions of the skill set, (5) selecting the top ten factors which account for variability in performance associated with the skill set, (6) proposing positively-phrased descriptors of the skill set at five performance levels ranging from "novice" to "expert"; (7) articulating and agreeing on five attributes associated with each performance level for the top ten factors, and (8) testing the classification and measurement scheme by reflecting on performance of individuals at each performance level in several different contexts.

The new performance measure can be used as either analytic or holistic rubrics for assessing and evaluating engineering design process skills. They provide a means for an assessor ("measurer") or student ("learner") to distinguish skills levels in engineering (performance chart); apply a comprehensive design process assessment rubric to a performance activity; and utilize a design process evaluation rubric. The flexibility of the rubrics permits easy selection of topics or skills to include in an assessment or evaluation exercise, if the measurer or learner wishes to focus on a subset of specific skills.

The development methodology encourages the use of a broad base of expertise to make the rubric outcomes widely applicable rather than discipline specific. The methodology can generate or stimulate discussion during faculty training regarding assessment activities in general, or as applied to a specific course. Suggestions for use of the performance measure are given to integrate these new measurement tools in engineering design activities or courses. 


\section{Background on Performance Measures and Rubrics}

In order to accurately assess or evaluate the quality of an engineering process design activity, thought must first go into the components, attributes, or behaviors that constitute an outstanding design process, as well as an outstanding process design engineer. Once these attributes or criteria have been established, performance measurements or rubrics can be designed to guide or prompt an assessor or evaluator to look for outcomes from a performance activity related to the desired criteria. A "performance activity" for the purposes of process design is defined as any activity by an individual, a group or team, or an individual within a group or team that is working towards achieving the goals and learning outcomes of the design assignment or project. Examples of performance activities would include but are not limited to group meetings or work sessions, oral presentations, meetings and interactions with the "customer" or "client" of the design project (such as faculty, industrial sponsor, or entity receiving the final product of the design project), written reports and memos, or brain storming sessions.

The need for and purpose of quality rubrics to assess or evaluate a performance activity are discussed elsewhere (Bargainnier, 2002). Rubrics that are developed can be either analytical in nature, which are designed to allow a student to self-assess a complex performance, process, or learning skill (Bargainnier, 2002), or can be used by an external assessor (not a participant in the performance activity) to as sess and provide feedback to an individual student or group or team of students. Analytic rubrics allow both the measurer and the learner to see what the strengths and weaknesses of a performance are, and aid gaining insights to identify areas for improvement. Analytic rubrics are most often task specific (e.g., dribbling a basketball, designing a heat exchanger), and would not necessarily make sense if applied to another skill or activity (Bargainnier, 2002).

Holistic rubrics require the measurer to score the overall process or product as a whole, without judging the component parts separately (Nitko, 2001). Holistic rubrics are more often viewed as evaluation measures than assessment measures, as there is less opportunity for feedback from the measurer about specific tasks or skills to improve future performances of the individual or group being assessed. When applied to assessing or evaluating the design process, holistic rubrics are generally easier and quicker to use, as the measurer is relying on their knowledge, expertise, and experience concerning the final outcomes from the design process, not the quality or mastery of individual tasks or elements of the design process itself.

Assessment rubrics or performance measures can become evaluation rubrics. A measurer assigns points or weighting factors to activities or skills on an assessment measure, and reaches a total score for the performance activity. This score is interpreted to evaluate whether or not the individual or group measured has achieved the desired goals and outcomes set by the measurer. Rubrics of this type, where individual tasks are evaluated and scored, combine the most powerful aspect of assessment (providing feedback to the learner), while allowing grading and evaluation. However, these rubrics can be very time consuming to utilize, should be made available to the learner in advance so that the learner understands expectations for the performance activity, and need to be returned to the learner in a timely manner to provide useful feedback.

\section{Building a Performance Measure for the Engineering Design Process}

As part of a two-day workshop at Western Michigan University in July 2002, a diverse group of faculty and administrators created a performance measure or rubric for the engineering design 
process. The measure consists of three parts, which are found as Tables 1, 2, and 3: (1) a performance chart for the design process; (2) a design process assessment rubric and (3) a design process evaluation rubric. The methodology to design the measure will be described, including the amount of time necessary to reasonably complete each of the steps in the process.

\section{Forming a Diverse Team to Design the Performance Measure}

In order to broaden the applicability of the resulting performance measure or rubric, a rubric design team with diverse training and perspectives is a necessity. Although the final rubric was intended for use in engineering design courses, other disciplines and areas of expertise which contribute to the success of engineering learners must be included. Varying perspectives, including level of faculty seniority, years of service at a particular university, real world or industrial expertise, and participation by students should be considered. The rubric design team that was assembled consisted of a facilitator with a background in mathematics and information technology, and 13 faculty (professors, associate professors, assistant professors, and instructors) from six universities (public and private; 3,000 to 30,000 enrolled students), many with past experience at other universities or in industry. Team members were from diverse disciplines, including chemical, civil, mechanical, electrical and computer engineering; English literature and composition; engineering communication; and rhetoric and technical communication, and several participants hold an MBA in addition to their doctoral degree. Four of the faculty currently teach senior level capstone design courses, and all of the engineering faculty actively incorporate elements of the design process and supporting activities into their classes. The rubric design team included two university administrators (Associate Dean of Engineering; Vice President of Research Services) who occasionally teach classes, ranged in age from 30 to 66 , and included 5 women and 9 men. Although graduate or undergraduate students and people currently practicing in industry were not part of the rubric design team, their potential contribution to the development of the rubric was recognized and valued.

\section{Selecting a Facilitator}

Selecting a facilitator to lead activities to design a performance measure or rubric is an integral part of the process. The facilitator must be familiar with the topic for which a measure is being developed; must be versed in the methodology being applied; and be unbiased in her actions in leading activities. The facilitator can be an active participant in the design team by contributing materials and ideas to the process of designing the performance measure or rubric, but she cannot let her own input dominate the final outcome.

\section{Synthesizing a Definition}

In order to develop a performance measure for any topic, a definition of what is being measured is needed. The design team broke into groups of 3 or 4 , with each small group trying to reflect the diversity of the entire design team (mixture of disciplines, experience, sex). In a twenty minute time period, each group wrote its understanding of the engineering design process, and entered it onto a laptop computer that used a projection system to make the statements visible throughout the room. All descriptions were reviewed and discussed by the entire design team, and the best features of each extracted. The original statements developed by each small group are given below.

Original statements by the small groups

- A design process involves interaction with a client to develop a product, method, or system that meets the needs of a user. 
- Design is an iterative process involving definition of needs, brainstorming possible solutions, exploring and testing alternative approaches, identifying optimal solutions, implementing selected designs, and documenting and communicating elements of the design and the process to a multiple audience, as appropriate.

- Design is an iterative process in which various alternatives are morphed into a final process or product within specified constraints. Often the alternatives are derived from optimizing with respect to various resources or constraints.

- What is the design process?

... a systematic development of a process or system to meet a set of customer specifications.

....using past experience or knowledge to synthesize a process or system to meet specified needs

....procedure for assembling available resources into a desired goal or product

- The design process is a systematic approach for creating a solution that addresses a need. The design process, while systematic, is creative and iterative. This involved clear identification of need, criteria for success, identifying the key issues, generating, analyzing, and evaluating the solution paths, implementing and assessing the solution for continuous improvement.

A single cohesive statement was synthesized by two people to represent the efforts of the entire design team. The synthesized statement was reviewed by the entire design team, edited, and accepted. The time to acceptance of the final statement was one hour. The final synthesized statement on defining the design process is found below.

\section{Synthesized statement from entire design team, 'What is the design process?'}

Design is a systematic, interactive, and iterative development of a process, system or product to meet a set of specifications. It often involves working with a client to meet their perceived needs within a set of explicit and implicit constraints. It is frequently team-based and initially involves detailed needs analysis, problem definition, deployment of prior knowledge and past experience, generating and analyzing possible solutions, and exploring alternative solution paths. As the process moves forward, designers identify optimal solutions, implement selected designs, document progress, and communicate elements of the design and its process of development to multiple audiences. Often solution alternatives are derived from optimizing with respect to various resources or constraints, integrating solutions to sub-problems, and recycling components of previous designs. As they evolve, design solutions are regularly validated against performance criteria and timetables that are either agreed upon at the beginning of the process or re-negotiated at specific milestones. Throughout the entire process, participants are committed to continuous improvement in design methodology, design tools, and personal/team capabilities that are valuable to future clients. 


\section{Behaviors and Characteristics of a Successful Design Process}

\section{Compiling characteristics or attributes of the design process}

The small groups were reconvened, and given twenty minutes to list characteristics or attributes of a successful design process, based on behaviors that should be exhibited by a person who is a successful designer. At the end of the twenty minutes, the items were compiled into a master list on the laptop projection system. Each small group stated one of its attributes in a round-robin fashion, until all characteristics originated by the small groups were included on the master list. Characteristics were combined, when appropriate, during the data entry process. The list of characteristics originated by the small groups is given in Table 4, as items 1 through 20.

\section{$\underline{\text { Rank-ordering the design process characteristics }}$}

Each small group was given twenty minutes to rank-order its 10 most important characteristics from the master list of 20 items, with " 1 " being the most important. The rank-ordering was entered in the laptop in the same round-robin fashion as earlier. Those characteristics with the highest number of occurrences of being selected were grouped together and reviewed. Each small group designated one characteristic as its most important, with agreement from the other small groups that the characteristic deserved to be in a group of "top 5 characteristics." After completing the "top 5 group," all other characteristics were discussed for inclusion on a list of 10 preferred characteristics (which includes the "top 5 group"), regardless of their ranking. Any characteristic that received support from the majority of the small groups (each group voted "yes" or "no" at the end of discussion about a characteristic) was included in the list of 10 preferred characteristics. Discussion of this sort continued until a list of 10 preferred characteristics was synthesized. At this point, any small group could request the removal of any item on the list of top 10 preferred characteristics, and replace it with any characteristic not already on the list. This occurred if the characteristic to be added received support from a majority of the small groups, per the previously described voting mechanism.

\section{Discussion and negotiation as part of the rank-ordering process}

The process of finalizing the list of top 10 characteristics took approximately 2 hours. The rankordering of all 20 characteristics, the final list of top 10 characteristics, and those characteristics not selected are included in Table 4. For example, "Problem definition" was selected by three small groups (ranked 5, 4, and 5), and combined during the discussion phase with "needs analysis, customer's specs within constraints," which was also selected by three small groups (ranked 10, 5, and 5). After discussion, negotiation, and voting by all the small groups, "Problem definition" was designated as the most important characteristic for the design process. This negotiation phase is an important part of designing performance measures or rubrics, as illustrated by the selection of item 9 in Table 4. "Teamwork" was originally selected only once during the ranking of all 20 of the compiled characteristics. After discussion, negotiation, and voting, it was included in the top 10 characteristics list, while other characteristics initially selected more often (for example, items 12, 13, and 17 in Table 4) were not included.

Item 6 was a final compilation of a number of topics dealing with deciding on the best design process to follow, exploring alternative methods and solutions, and optimization of process and products to meet defined goals or specifications.

\section{Designating related pairs of characteristics}

The top 10 characteristics from Table 4 were matched into related pairs, as shown in Table 5. Each letter (A, B, C, D or E) designates the pairing selected by consensus of the entire design team. 
A definition statement for each characteristic was written during an additional discussion period (45 minutes), and may be found in Table 6. The bold titles in each pair represent the characteristic that will be incorporated as a "Performance Area" in the final version of the rubrics developed during the workshop (see Tables 1, 2, and 3).

\section{The Five Skill Levels and Related Attributes of a Successful Designer}

Thirty minutes of discussion by the entire design team was needed to decide on titles to be used in the performance measure or rubric for each of the five skill levels associated with being a successful designer. The titles in Table 7 must accurately reflect the skill level of a person performing an activity in a design process. Titles were selected to avoid negative connotations and stereotyping. Each small design group was assigned a lettered pair of characteristics (Table 6), and asked to synthesize a definition, attributes, or behaviors for each of the five skill levels of a designer (Table 7). These behaviors were discussed and edited by the entire design team, and are found in final form in Table 8 . Consensus on the definitions found in Table 8 was reached during a two-hour work period.

\section{Completing the Performance Measure for the Engineering Design Process}

Formulating concise descriptors for each performance area

The ten paired characteristics (Table 6), form the "Performance Areas" that are to be measured by the rubrics that were developed (Tables 1, 2, and 3). For each performance area, five key activities or tasks were defined, based on the descriptors and behaviors recorded in Tables 6 and 8. These performance areas, tasks, and activities are in the left-most column of rubric Tables 1, 2, and 3. Formulating these concise descriptors was completed during a one-hour discussion session of the entire design team.

\section{Concise descriptor for each skill level in the final performance measure}

Each of the small groups worked with their previously assigned paired characteristics (Table 5 or 6) to get a one- or two-word phrase that succinctly describes the level of expected skill or competence for an activity or task related to each of the five skill levels of a successful designer (Table 7). These phrases were reviewed, edited, and approved by the entire design team in a twohour work period, and are found in the performance chart of Table 1.

\section{Using the Performance Measure for the Engineering Design Process}

\section{General Information and Observations}

In order to successfully use the performance measures or rubrics developed for the engineering design process, the assessor (measurer) needs to be familiar with the 10 performance area definitions (Table 6), and understand the five skill levels (Table 8). Strong vocabulary skills are needed for the Table 1 performance chart.

Most learners (individual, team, or individual within a team) will consistently perform at the same skill level (trainee, intern, etc.) across the performance tasks or activities. As skills improve in a particular area, a learner should progress to higher skill levels during subsequent observations by an assessor. The assessor may want to review a rubric with the learner prior to its use, so that the learner is aware of expectations for the performance activity. Not all activities may be witnessed by the assessor in an observation period, but a completed rubric would provide a compilation of the

activities that did occur. The completed rubric also provides a means of recording whether or not 
performance activities that were expected to be observed actually occurred.

\section{Using the Performance Chart (Table 1)}

The Performance Chart for Design Process (Table 1) is an analytic rubric that can be used for detailed assessment of specific skills associated with the design process for an individual or team performance activity. This rubric is intended to be a fast assessment rubric, providing "real time" feedback to the learner. The appropriate phrase or word for a skill level for each task in a performance is highlighted or circled by the assessor as the activity or task is observed. The assessor can give the rubric to the learner and discuss the assessment immediately following the end of the design process task or activity.

\section{Using the Assessment Rubric (Table 2)}

The Design Process Assessment Rubric (Table 2) uses the same performance areas and tasks or activities as Table 1. Table 2 requires the assessor to give feedback in the form of comments or suggestions in utilizing the strengths, weaknesses, and insights mechanism discussed earlier. Table 2 is an analytical rubric, but would not be as fast to use as Table 1, as individual comments need to be written, rather than just highlighting the appropriate phrase or word. Table 2 may be a more preferred style of feedback by an assessor or learner, depending on their personal preference, and it requires less understanding of the vocabulary used in Table 1.

\section{Creating the Weightings for the Evaluation Rubric (Table 3)}

Table 3 is the Design Process Evaluation Rubric. The performance tasks or activities were weighted by the entire design team that developed the rubrics (two-hour work period). To arrive at a weighting system, the design team was divided into four small groups. Each small group weighted the 10 performance areas (Table 6), so that the total sum of points across the 10 performance areas is 200. Each small group divided the points for each performance area amongst the tasks or activities within that area. The weighting system that resulted from each of the small groups was reviewed, and a consensus was reached by the entire design team on the final weighting system. The weightings for the performance areas and each engineering design process task or activity are shown in Table 3.

\section{Using the Evaluation Rubric (Table 3)}

This rubric retains some features of an analytic rubric, but is moving towards a holistic rubric. An assessor can consider the "weight" column to be points possible to assign for mastery of a particular task, or use them as a multiplier for each activity or task, if they chose to use some other

scoring scale (e.g., evaluate each task or activity on a scale of 1 to 5, and multiply by the weighting factor). A final score can be arrived at, and an overall grade assigned to the individual learner or team that is evaluated. Table 3 would be less useful than Table 1 or 2 as an assessment tool, as was discussed previously in the Background section.

\section{Suggested Uses of the Engineering Design Process Performance Measure}

The performance measure or rubrics as designed are flexible in nature, and can be used in a variety of contexts. The assessor can choose to use only portions of any of the rubrics, depending on what performance areas they are assessing or evaluating. Current uses of the rubrics have made use of 
this flexibility, by having students to use parts of the rubrics as peer-assessment tools for observing other members of their design teams. The peer assessments are then discussed with the learner.

Students have also been given relevant portions of the rubrics, as decided by a faculty member, to use in self-assessing their contribution to team activities. Students discuss their own personal strengths, weaknesses, and insights as part of a written report reflecting on their engineering design projects. These self-ass essments have been used both during an ongoing project, which would allow time for the learner to improve their individual performance in their current work, and as a post-project assessment mechanism to reflect on whether learning outcomes and goals were achieved. Faculty from several different engineering disciplines have used the rubrics to evaluate student design group performances, and the rubrics can be one element in determining final course grades.

\section{Benefits to Engineering Educators}

This paper documents a detailed method for creating performance measures or rubrics for assessing or evaluating the engineering design process. This development methodology can be used to originate assessment related materials for other topics. The performance measures that were developed at Western Michigan University provide information or topic areas for faculty to assess or evaluate student learning, or for use as a peer- or self-assessment mechanism. The rubrics provide a means to standardize assessment or evaluation activities for courses that are taught by more than one faculty member in the same semester, or by different faculty members from one academic year to the next. The measures are especially applicable to senior capstone design courses, which are important components for many universities to demonstrate that ABET 2000 Criterion 3 topics are being met, but they are also useful in other undergraduate courses which contain elements of the engineering design process. The flexibility of the rubrics allows the user to select which topics or skills to include in an assessment or evaluation exercise, if the assessor or learner wishes to focus on a subset of specified skills.

In general, performance measures or rubrics could be designed using the development methodology to aid in the standardization of ABET-type assessment materials across a department, college, or university. The development methodology encourages the use of a broad base of expertise to make the outcomes widely applicable rather than discipline specific. The methodology can be used to generate or stimulate discussion during faculty training regarding assessment activities in general, or as applied to a specific course. It can assist new faculty or those new to assessment or evaluation activities by providing structured guidance, for either broad or specific applications.

\section{References}

Parker, P.E., P.D. Fleming, S. Beyerlein, D. Apple, and K. Krumsieg, "Differentiating Assessment from Evaluation as Continuous Improvement Tools," Proceedings of the $31^{\text {st }}$ ASEE/IEEE Frontiers in Education (FIE) Conference, Reno, NV, paper 1462, October 2001.

Bargainnier, S., "Fundamentals of Rubrics," module from the Faculty Handbook ${ }^{\odot}$, S. Beyerlein, Ed., copyright held by Pacific Crest, Lisle, IL (2003).

Nitko, A.J., Educational assessment of students ( $3^{\text {rd }}$ ed.). Upper Saddle River, NJ: Merrill (2001). 
Performance Activity:

\begin{tabular}{|c|c|c|c|c|c|}
\hline Performance Area & Trainee & Intern & Apprentice Designer & Senior Designer & Expert Designer \\
\hline \multicolumn{6}{|l|}{ Problem Definition: } \\
\hline Identify Needs & Perfunctory & Locked on one & Sees several & Ranked set & Contrasted set \\
\hline Establish Requirements & Unsure of need & Sees the need & Defines some & Defines most & Paints big picture \\
\hline Identify Constraints & Disregards & One at a time & Two at a time & Sensitive to all & Places all in system \\
\hline Define Functions & Open-ended & Primary use & Secondary use & Multiple use & Customized multiple use \\
\hline Perception Check & Plays role wanted & Does what told & Values the role & Fulfills the role & Facilitates inquiry \\
\hline \multicolumn{6}{|l|}{ Prior Knowledge: } \\
\hline Locate/review resources & Minimal Effort & Basics & readily available & Extensive in discipline & Extensive all disciplines \\
\hline Use of Principles & Uses inappropriately & obvious & well-known & subtle \& well-developed & essential \& complete \\
\hline Evaluate external info & Seldom evaluates & Often misuses & approved by others & Critically evaluates & Correctly evaluates \\
\hline Internalized knowledge & Superficial & Partial & Adequate & Extensive & Nationally recognized \\
\hline Professional Growth & Only when forced & When challenged & reactive & Proactive & Continuous \\
\hline \multicolumn{6}{|l|}{ Divergent Thinking: } \\
\hline Quantity & Few & Some & Several & Large & Extensive \\
\hline Distinctively unique & Couple & Few & Some & Several & Large \\
\hline Out of the norm & Rarely & Seldom & Often & Couple & Several \\
\hline Causes redefinition & Rarely & Seldom & Occasionally & Often & Couple \\
\hline Out of the box & Improbably & Rarely & Occasionally & Often & Consistently \\
\hline \multicolumn{6}{|l|}{ Professional Analysis: } \\
\hline Uses key parameters & Limited/Many Extra & Some/Few Extra & Nearly all/Often Extra & All/Rarely Extra & Right on \\
\hline Toolbox/usage & Small/Ineffectual & Limited/Basic & Standard/Marginal & Comprehensive/effective & Tool builder/master \\
\hline Estimating & Way off & Sporadic accuracy & Consistently in ballpark & Consistently close & Intuitively correct \\
\hline Experimenting & Random trials & Uses given experiments & Adapts experiments & Designs experiments & Creative experiments \\
\hline System modeling & Simplistic & Bare bones & Nearly complete & Deals with boundaries & Integrates other models \\
\hline \multicolumn{6}{|l|}{ Decision Making: } \\
\hline Includes stakeholders & Unaware who they are & Incorporates obvious & Knows them all & Accounts for all & Takes every perspective \\
\hline Consensus & Rarely & Seldom & Occasionally & Often & Consistently \\
\hline Cost-Effective & Oblivious & Not under control & Reasonable & Consistently controlled & Very efficient \\
\hline Uses design criteria & Sporadically & Minimally & Periodically & Frequently & Consistently \\
\hline Justification & Randomly & Occasionally & Dependably & Frequently & Always \\
\hline
\end{tabular}




\begin{tabular}{|c|c|c|c|c|c|}
\hline Performance Area & Trainee & Intern & Apprentice Designer & Senior Designer & Expert Designer \\
\hline \multicolumn{6}{|l|}{ Create \& Follow Plan: } \\
\hline Defines tasks & Sporadic & Rudimentary & Contributes & Thoughtful & Visionary \\
\hline Outlines milestones & Unaware & Short Range & Executes & Modifies & Originates \\
\hline Track \& revise plan & Disjointed & Passive & Supports & Implement Change & Assesses \\
\hline Document Progress & Incoherent & Perfunctory & Methodical & Complete & Comprehensive \\
\hline \multicolumn{6}{|l|}{ Iterate \& Assess: } \\
\hline Frequency & Sporadic & Methodical & Consistent & Continuous & Parallel Processing \\
\hline Review previous cycles & Seldom & Most Recent & Tries to extend & Captures most & Integrates all \\
\hline Assess design process & Only moves forward & After big steps & At trouble steps & After all steps & Continuously \\
\hline Assess design solutions & Only when caught & When things go wrong & When uncomfortable & When substandard & To optimize \\
\hline Effective iteration & Haphazard & When required & In obvious situations & Purposefully & For significant value \\
\hline \multicolumn{6}{|l|}{ Validate Solutions: } \\
\hline Interpret Requirements & Oblivious & Knows obvious ones & Knows them all & Meets them all & Exceeds them all \\
\hline Mediate Requirements & Unaware of conflict & Minimal help & Can be helpful & Fairly effective & Leaves all satisfied \\
\hline Build Test Plan & Attempts & Sketchy & Plan with holes & Solid & Elegant \\
\hline \multicolumn{6}{|l|}{ Communication: } \\
\hline Written reports & Unintelligible & Superficial & Mechanical & Informative & Comprehensive \\
\hline Oral communication & Often Incoherent & Inconsistent & Transmits & Purposeful & Persuasive \\
\hline Project documentation & When dictated & Personally useful & Limited audience & Substantive & Thorough \\
\hline Visuals \& graphics & Confusing & Elementary & Supportive & Illustrative & Interpretive \\
\hline Professionalism & Unaware & Uncomfortable & Attempts & Consistent & Polished \\
\hline \multicolumn{6}{|l|}{ Teamwork: } \\
\hline Use of resources & Minimal & Responds & Requests & Seeks out & Gets the best \\
\hline Managing conflicts & Potential troublemaker & Silent observer & Part of solution & Steps in to resolve & Learning experience \\
\hline Shared Consensus & Not on board & Willing to go along & Sees the vision & Acts on vision & Shapes vision \\
\hline $\begin{array}{l}\text { Belonging/Commitmen } \\
\mathrm{t}\end{array}$ & Erratic & Compliant & Sees benefits & Enrolled & Committed \\
\hline Performing Roles & Plays role wanted & Does what told & Values the role & Fulfils the role & Facilitates all roles \\
\hline
\end{tabular}

Comments 
Table 2. Design Process Assessment Rubric

Performer

Assessor

Date

Performance

Activity:

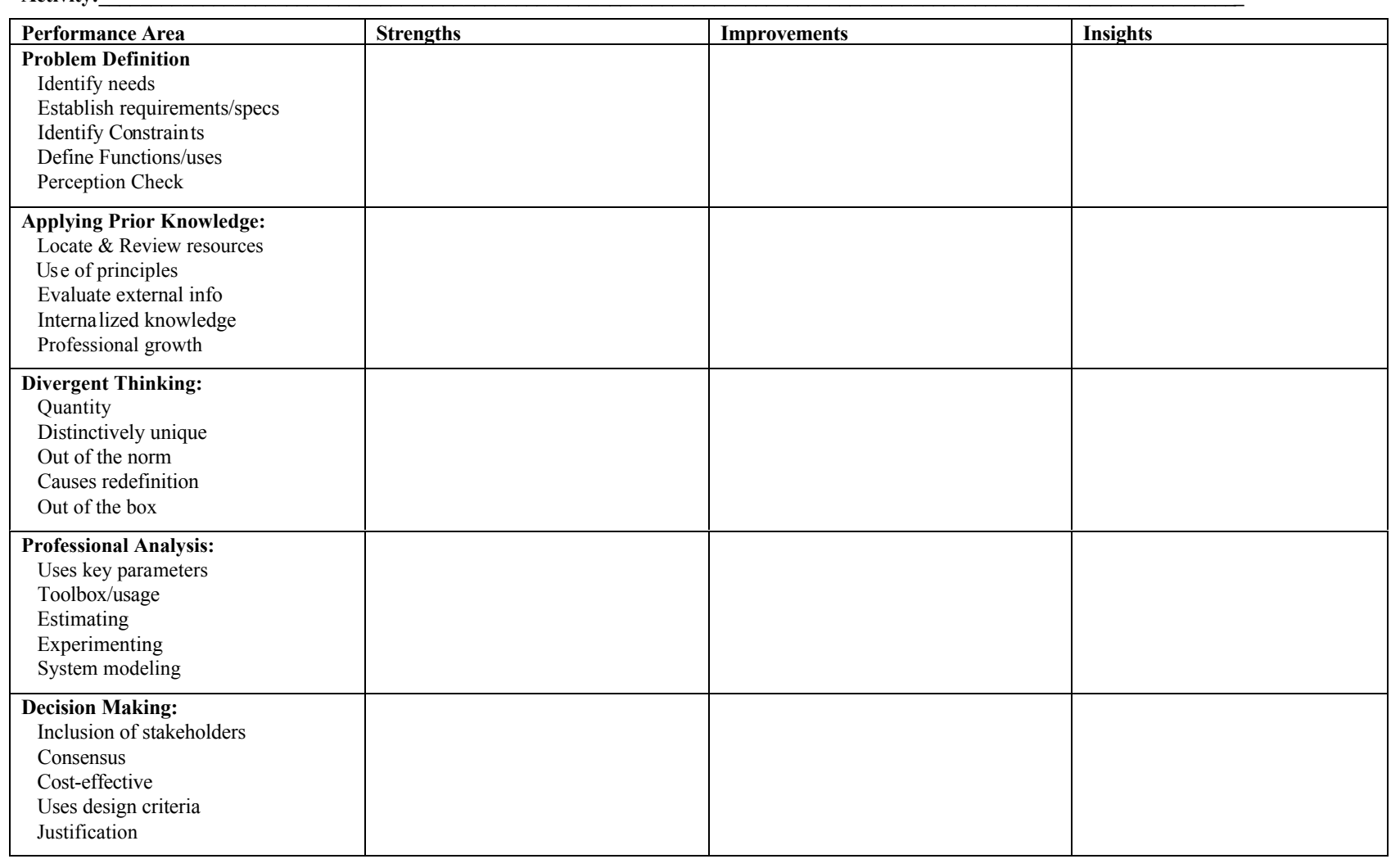




\begin{tabular}{|c|c|c|c|}
\hline Performance Area & Strengths & Improvements & Insights \\
\hline $\begin{array}{l}\text { Create and Follow plan } \\
\text { Defines tasks } \\
\text { Outlines milestones } \\
\text { Organized \& logical } \\
\text { Track \& revise plan } \\
\text { Document progress }\end{array}$ & & & \\
\hline $\begin{array}{l}\text { Iterating and Assessing } \\
\text { Frequency } \\
\text { Review previous cycles } \\
\text { Assess design process } \\
\text { Assess design solutions } \\
\text { Effective iteration }\end{array}$ & & & \\
\hline $\begin{array}{l}\text { Solution Validation: } \\
\text { Interpret requirements } \\
\text { Mediate requirements } \\
\text { Build test plan } \\
\text { Test against criteria } \\
\text { Stakeholder acceptance }\end{array}$ & & & \\
\hline $\begin{array}{l}\text { Communication: } \\
\text { Written reports } \\
\text { Oral communication } \\
\text { Project documentation } \\
\text { Visuals \& Graphics } \\
\text { Professionalism }\end{array}$ & & & \\
\hline $\begin{array}{l}\text { Teamwork: } \\
\text { Use of resources } \\
\text { Managing conflicts } \\
\text { Shared consensus } \\
\text { Belonging/commitment } \\
\text { Performing roles }\end{array}$ & & & \\
\hline
\end{tabular}

Comments 
Table 3. Design Process Evaluation Rubric Performer

Date

Performance Activity:

\begin{tabular}{|c|c|c|c|c|c|c|c|}
\hline Performance Area & $\begin{array}{l}\text { Raw } \\
\text { Score }\end{array}$ & Weight & \begin{tabular}{|l|} 
Adjusted \\
Score \\
\end{tabular} & Performance Area & $\begin{array}{l}\text { Raw } \\
\text { Score }\end{array}$ & Weight & $\begin{array}{l}\text { Adjusted } \\
\text { Score }\end{array}$ \\
\hline $\begin{array}{l}\text { Problem Definition } \\
\text { Identify needs } \\
\text { Establish requirements } \\
\text { Identify Constraints } \\
\text { Define Functions/uses } \\
\text { Perception Check }\end{array}$ & & $\begin{array}{l}9 \\
7 \\
7 \\
7 \\
5\end{array}$ & & $\begin{array}{l}\text { Create and Follow plan } \\
\text { Defines tasks } \\
\text { Outlines milestones } \\
\text { Organized \& logical } \\
\text { Track \& revise plan } \\
\text { Document progress }\end{array}$ & & $\begin{array}{l}\mathbf{3} \\
\mathbf{3} \\
\mathbf{3} \\
\mathbf{3} \\
\mathbf{3}\end{array}$ & \\
\hline $\begin{array}{l}\text { Applying Prior Knowledge: } \\
\text { Locate/Review resources } \\
\text { Use of principles } \\
\text { Evaluate external info } \\
\text { Internalized knowledge } \\
\text { Professional growth }\end{array}$ & & $\begin{array}{l}5 \\
5 \\
3 \\
4 \\
3\end{array}$ & & $\begin{array}{l}\text { Iterating and Assessing } \\
\text { Frequency } \\
\text { Review previous cycles } \\
\text { Assess design process } \\
\text { Assess design solutions } \\
\text { Effective iteration } \\
\end{array}$ & & $\begin{array}{l}2 \\
3 \\
3 \\
3 \\
4\end{array}$ & \\
\hline $\begin{array}{l}\text { Divergent Thinking: } \\
\text { Quantity } \\
\text { Distinctively unique } \\
\text { Out of the norm } \\
\text { Causes redefinition } \\
\text { Out of the box }\end{array}$ & & $\begin{array}{l}2 \\
5 \\
5 \\
4 \\
4\end{array}$ & & $\begin{array}{l}\text { Solution Validation: } \\
\text { Interpret requirements } \\
\text { Mediate requirements } \\
\text { Build test plan } \\
\text { Test against criteria } \\
\text { Stakeholder acceptance } \\
\end{array}$ & & $\begin{array}{l}2 \\
2 \\
2 \\
2 \\
2\end{array}$ & \\
\hline $\begin{array}{l}\text { Professional Analysis: } \\
\text { Uses key parameters } \\
\text { Toolbox/usage } \\
\text { Estimating } \\
\text { Experimenting } \\
\text { System modeling }\end{array}$ & & $\begin{array}{l}3 \\
3 \\
5 \\
5 \\
4 \\
\end{array}$ & & $\begin{array}{l}\text { Communication: } \\
\text { Written reports } \\
\text { Oral communication } \\
\text { Project documentation } \\
\text { Visuals \& Graphics } \\
\text { Professionalism } \\
\end{array}$ & & $\begin{array}{l}6 \\
6 \\
6 \\
2 \\
5 \\
\end{array}$ & \\
\hline $\begin{array}{l}\text { Decision Making: } \\
\text { Inclusion of stakeholders } \\
\text { Consensus } \\
\text { Cost-effective } \\
\text { Uses design criteria } \\
\text { Justification } \\
\end{array}$ & & $\begin{array}{l}4 \\
4 \\
4 \\
4 \\
4 \\
\end{array}$ & & $\begin{array}{l}\text { Teamwork: } \\
\text { Use of resources } \\
\text { Managing conflicts } \\
\text { Shared consensus } \\
\text { Belonging/commitment } \\
\text { Performing roles }\end{array}$ & & $\begin{array}{l}3 \\
4 \\
5 \\
5 \\
3 \\
\end{array}$ & \\
\hline
\end{tabular}


Table 4. Performance Characteristics for Design

(shown with rank-ordering given by the small groups)

\begin{tabular}{|ll|}
\hline "Top 10" Characteristics after rank-ordering & \\
\hline 1. Problem definition & $5,4,5$ \\
2. Communication, documenting & $10,5,5$ \\
3. Applying prior knowledge, principles, existing solutions & 10,9 \\
4. Divergent thinking, generating alternatives & 9,8 \\
5. Solution Validation & $8,7,1$ \\
(meets customer specs) & 10,4 \\
6. Decision making/evaluating alternatives & $3,5,3,1$ \\
7. Create and follow a design plan & \\
8. Professional analysis, modeling, testing proposed solutions & $7,3,2$ \\
9. Teamwork & 5,1 \\
10. Iteration & 8,2 \\
$\quad$ (Assessing the process) & 6 \\
\hline & 4,3 \\
\hline Non-Selected Items (some integrated above after extensive group discussion) & $6,4,2$ \\
\hline 11. Optimizing & 6 \\
12. Evaluating existing solutions & \\
13. Creating professional specifications & 6,5 \\
14. Clear inventory of available resources & 9 \\
15. Brainstorming & 6 \\
16. Project Management & 5,1 \\
17. Meeting societal standards & 4,1 \\
18. Documenting the process & \\
19. Taking Action & \\
20. Lateral Thinking & \\
\hline
\end{tabular}

Table 5. Pairing of Performance Characteristics

\begin{tabular}{|c|l|}
\hline $\begin{array}{c}\text { Pair } \\
\text { Designation }\end{array}$ & \multicolumn{1}{|c|}{ Characteristic for design, in same order as presented in Table 4} \\
\hline \hline A & Problem definition (needs analysis, customer's specs within constraints) \\
\hline B & Communication, documenting \\
\hline C & Applying prior knowledge, principles, existing solutions \\
\hline C & Divergent thinking, generating alternatives \\
\hline A & Solution Validation - meets customer specs \\
\hline D & Decision making/evaluating alternatives \\
\hline E & Create and follow a design plan \\
\hline E & Professional analysis, modeling, testing proposed solutions \\
\hline B & Teamwork \\
\hline D & Iteration/Assessing the process \\
\hline
\end{tabular}




\section{Table 6. Paired Characteristics ("Performance Areas") with their Descriptors}

A. Problem Definition:
Interviewing client, needs analysis, identifying issues \& constraints, developing specifications, define
functions/uses, perception check
Solution Validation:
Interpreting \& mediating requirements, creating an appropriate test plan, measuring for success,
satisfying societal requirements, upholding professional responsibilities, customer acceptance
B. Communication:
Informing client/teammates, personal documentation, oral presentations, written reports,
visual and graphic elements, professionalism
Teamwork:
Belonging, commitment, ownership, cooperation, performing within roles, managing conflicts,
efficiently using/creating resources
C. Prior Knowledge:
Locating \& review available resources, applying existing knowledge/principles/solutions,
evaluate external information, depth \& breadth of internalized knowledge, identifying learning needs
Divergent thinking:
Brainstorming, generating alternative solutions, quantity, uniqueness, novelty, problem reformulation
D. Decision Making:
Inclusion of stakeholders, evaluating alternatives against criteria, justifying selection,
cost-effectiveness, level of consensus obtained
Iterating \& Assessing:
Ongoing, captures and applies lessons learned from prior iterations, assess solutions,
assess process followed, oriented toward continuous improvement
E. Create/follow plan:
Tasks and milestones clearly defined, logical \& organized plan/timetable,
taking action, documentation of progress
Professional Analysis:
Appropriate tool selection, tool proficiency, parameter identification, system modeling,
sensitivity analysis, estimating, experimenting, optimization

Table 7. Five Skill Levels of a Successful Designer

\begin{tabular}{|c|}
\hline Expert Designer \\
\hline Senior Designer \\
\hline Apprentice Designer \\
\hline Intern \\
\hline Trainee \\
\hline
\end{tabular}




\section{Table 8. Behaviors for Distinguishing Skill Levels in the Engineering Design Process}

(Initial letter corresponds to "Performance Area" assigned by Tables 5 or 6)

\section{Expert Designer}

A. Achieves a creative solution encompassing customer and societal needs, while meeting all applicable professional requirements.

B. Supports efficient and timely achievement of project milestones, deployment of team resources, and extraordinary group dynamics including clear, thorough, and useful communication of project needs, activities, findings, and recommendations.

C. Masterfully uses divergent thinking, in-depth knowledge and existing processes to develop multiple creative solutions.

D. Always exercises professional judgment, expert knowledge, and design criteria to evaluate and make recommendations on potential solutions, continuously improving the design at all process stages.

E. Consistently applies quality analytical skills that produce professional plans that are easy to follow.

\section{Senior Designer}

A. Identifies, analyzes, and validates customer and societal needs, and professional requirements.

B. Directs others and coordinate communication that supports achievement of project milestones, deployment of team resources, and healthy group dynamics.

C. Routinely uses divergent thinking, in-depth knowledge and existing processes to develop multiple solutions of good quality.

D. Incorporates relevant professional standards and design criteria in evaluating alternative designs, leading to identifiable design improvements.

E. Can apply extensive analytical skills that lead to solid design plans that can be followed by others.

\section{Apprentice Designer}

A. Identifies and analyzes most customer and societal concerns, along with key professional requirements.

B. Contributes to project activities on request, assuming assigned roles, assisting in meeting most project milestones, and supporting team activities under some supervision.

C. Generates several feasible solutions in a mechanical way based on prior experience and knowledge.

D. Performs design tasks within well-defined project areas, and suggests incremental design changes.

E. Possesses sufficient analytical skills to produce marginally successful plans that are difficult to follow.

\section{Intern}

A. Collects information requested on customer needs, societal concerns, and professional requirements.

B. Assists in meeting some project and reporting milestones under extensive supervision.

C. Uses narrow knowledge base to build a limited set of alternatives.

D. Follows established procedures for gathering data and decision-making, occasionally leading to incremental design changes.

E. Can apply limited analytical skills as directed in plans made by others.

\section{Trainee}

A. Often ignores customer needs, societal concerns, and professional requirements.

B. Frequently works outside the team environment, leading to irregular and undependable progress toward project milestones. Communication activities are minimal or do not contribute to documenting or furthering project outcomes.

C. Locks on to first idea with exploring options, existing solutions, or considering alternatives.

D. Uses capricious and arbitrary standards to select among possible designs, and is sporadic in producing suggestions for design modification.

E. Often displays inferior analytical skills and seldom plans or follows plans. 